\title{
Patterns and trends of beverage consumption among children and adults in Great Britain, 1986-2009
}

\author{
Shu Wen $\mathrm{Ng}^{1}$, Cliona Ni Mhurchu ${ }^{2}$, Susan A. Jebb ${ }^{3}$ and Barry M. Popkin ${ }^{1 *}$ \\ ${ }^{1}$ University of North Carolina at Chapel Hill, 123 West Franklin Street, Chapel Hill, NC 27516-3997, USA \\ ${ }^{2}$ Clinical Trials Research Unit, The University of Auckland, Private Bag 92019, Auckland 1142, New Zealand \\ ${ }^{3}$ MRC Human Nutrition Research, Elsie Widdowson Laboratory, Fulbourn Road, Cambridge CB1 9NL, UK \\ (Submitted 14 March 2011 - Final revision received 10 August 2011 - Accepted 8 October 2011 - First published online 20 December 2011)
}

\section{Abstract}

Many dietary recommendations include reduction of excessive intake of sugar-sweetened beverages (SSB) and other energy-rich beverages such as juices and alcohol. The present study examines surveys of both individual dietary intake data and household food expenditure surveys to provide a picture of patterns and trends in beverage intake and purchases in Great Britain from 1986 to 2009 , and estimates the potential for pricing policy to promote more healthful beverage purchase patterns. In 2008-9, beverages accounted for 21 , 14 and $18 \%$ of daily energy intake for children aged 1.5-18 and 4-18 years, and adults (19-64 years), respectively. Since the 1990s, the most important shifts have been a reduction in consumption of high-fat dairy products and an increased consumption of fruit juices and reduced-fat milk among preschoolers, children and adolescents. Among adults, consumption of high-fat milk beverages, sweetened tea and coffee and other energy-containing drinks fell, but reduced-fat milk, alcohol (particularly beer) and fruit juice rose. In testing taxation as an option for shifting beverage purchase patterns, we calculate that a $10 \%$ increase in the price of SSB could potentially result in a decrease of $7.5 \mathrm{ml} /$ capita per d. A similar $10 \%$ tax on high-fat milk is associated with a reduction of high-fat milk purchases by $5 \mathrm{ml} /$ capita per $\mathrm{d}$ and increased reduced-fat milk purchase by $7 \mathrm{ml} /$ capita per $\mathrm{d}$. This analysis implies that taxation or other methods of shifting relative costs of these beverages could be a way to improve beverage choices in Great Britain.

Key words: Beverage intake: Sugar-sweetened beverages: Price: Great Britain

Rates of overweight and obesity have increased sharply in Great Britain since the mid-1980s. In 2009, 61.3\% of adults (aged 16 years or over), and 28.3\% of children (aged 2-10 years) in England were overweight or obese ${ }^{(1)}$. Improving the quality of the diet while also reducing per capita energy intake to achieve and maintain a healthy weight among the British represents a key policy objective ${ }^{(2-4)}$. The reduction of added sugars, specifically those from sugar-sweetened beverages (SSB; namely all energy soft drinks, fruit drinks and sugar-sweetened coffees and teas) and other high-energy beverages such as juices and alcohol, has been included in most documents concerned with obesity not only in Great Britain, but also globally ${ }^{(5,6)}$. In order to establish the likely impact of such changes, it is necessary to consider beverage intake patterns.

The biological basis for a policy to decrease sugarsweetened beverages to prevent obesity is the relationship between beverage intake and food intake. There appears to be little reduction in food intake when energy beverages are substituted for water and other low-nutritive sweetened or 'diet' beverages ${ }^{(7-9)}$. In addition, there is some evidence that the fructose component of sugars such as sucrose and highfructose corn syrup might lead to additional cardiometabolic risks $^{(10-14)}$. Individual studies are often inconsistent; however, meta-analyses of clinical and epidemiological research show a significant linkage of SSB with weight gain and a range of cardiometabolic risks ${ }^{(15-17)}$. Emerging data suggest that the effect of fruit juice consumption on weight gain and the risk of diabetes and other cardiometabolic outcomes is consistent with the SSB studies ${ }^{(18-22)}$. There are only a small number of studies comparing water as a substitute for these energy beverages; however, they consistently suggest that water intake may help to reduce energy intake ${ }^{(23,24)}$.

There are few systematic analyses of overall beverage patterns and trends at the national level. For the USA, a number of studies have examined overall patterns and found a large secular increase in both total energy intake from beverages and also the total volume of beverage intake other than water ${ }^{(25,26)}$. Both the USA and Mexico (a country that almost doubled its intake of energy from beverages

Abbreviations: EFS, Expenditure and Food Survey; NDNS, National Diet and Nutrition Survey; NFS, British National Food Survey; SSB, sugar-sweetened beverages.

*Corresponding author: Professor B. M. Popkin, fax +19199669159 (backup: 6638), email popkin@unc.edu 
between 1999 and 2006) obtain over $20 \%$ of their daily energy intake from beverages, with significant proportions from highsugar beverages including SSB and juices ${ }^{(27,28)}$. Elsewhere, there is a lack of systematic research on overall trends in beverage consumption at the national level.

An important question for researchers is to identify how changes in beverage intake may be stimulated. One approach seen as being potentially effective is taxation based on the amount of added sugar used ${ }^{(29,30)}$. In Great Britain, there is a growing literature on fat taxes, which concludes that welldesigned and targeted taxes could be useful in reducing the burden of nutrition-related diseases ${ }^{(31-33)}$ but there are limited studies looking at pricing policies on SSB.

The present study examines surveys of both individual dietary intake data and purchasing data in the context of household income and expenditures to provide a picture of patterns and trends in beverage intake and purchases in Great Britain over the 1986-9 period. In addition, it examines the potential for pricing policy to promote more healthful beverage purchase (and thus consumption) patterns.

\section{Data and methods}

\section{Data sources}

Dietary intake data. There have been five nationally representative surveys of dietary intake among selected age groups in Great Britain. They are the Dietary and Nutritional Survey of British Adults, 1986-7; the 2000-1 National Diet and Nutrition Survey (NDNS) of Adults aged 19-64 years; a 1997 NDNS of Young People aged 4-18 years; and the 1992 National Diet, Nutrition and Dental Survey of Children aged $1.5-4.5$ years. Beginning in 2008, the British government began the NDNS Rolling Programme, which collects nutrient intakes and nutritional status of people aged 1.5 years and older living in private households in Great Britain. Except for the 1986 survey, each survey used a multistage random probability sample with postal sectors as the primary sampling unit, thus sample weights were available for all the surveys to allow estimation of nationally representative measures.

However, there are critical differences in the data collection periods across the surveys that require complex statistical adjustments to provide statistically representative trends between the surveys. The 1992 survey among children (1.54.5 years) and the 2008-9 survey used a $4 \mathrm{~d}$ food records to quantify food and nutrient intakes, while the previous NDNS of adults (19-64 years) and young people (4-18 years) were conducted over $7 \mathrm{~d}$. This is pertinent because day-today variability for each individual means that diary duration may have an impact on survey estimates. Hence, to allow for all the analyses and comparisons to be done on a $4 \mathrm{~d}$ basis, we applied the methods outlined in the NDNS 2008-9 report $^{(34)}$ on the 1986-7 and 2000-1 adult, and the 1997 young people surveys to derive the means and standard errors by bootstrap sampling with replacement.

We also standardised the measurement of beverages across all the surveys. For energy from beverages, added milk and sugar for tea, coffee and other drinks were provided separately in the earlier food intake survey, but we could systematically link the results, so we are able to examine sweetened and unsweetened tea and coffee separately. Water consumption from both tap and bottle data was utilised from all surveys when possible; however, there is minimal understanding of the quality of the water measurement in most surveys conducted in Europe and the USA on this topic $^{(24)}$. Table 1 provides the beverage groups used, and their definitions, with examples.

Food purchase data. For 1975-2000, we utilised 5-year increments of the British National Food Survey (NFS), the longest-running continuous (annual) survey of household food purchases and expenditure in the world. The NFS was originally set up in 1940 by the then Ministry of Food to monitor the adequacy of the diet of urban 'working class' households in wartime, but it was extended in 1950 to become representative of households throughout Great Britain. In 1996, the survey was extended to cover the entire UK to be presented for the first time. The household member who did most of the food shopping was asked questions about the household and its food purchasing, and kept a diary for $7 \mathrm{~d}$, recording food coming into the household, including quantities, expenditure, food prices and some detail of the household meals (including snacks and picnics prepared from household supplies). We only used 5-year increments of the data due to the immensity of working with 25 years of raw data.

From 2001, the NFS was completely replaced by the Expenditure and Food Survey (EFS), which combined and superseded both the previous Family Expenditure Survey and the NFS. The EFS sample for the UK is a multistage stratified random sample with clustering. The survey is continuous, interviews being spread evenly over the year to ensure that seasonal effects are covered. Further information on sampling can be found in the user guide volume of the EFS documentation $^{(35)}$. The basic unit of the survey is the household, with each individual ( $\geq 16$ years) in the household keeping diary records of daily expenditure for 2 weeks. Information about regular expenditure, such as rent and mortgage payments, is obtained from a household interview along with retrospective information on certain large, infrequent expenditures such as those on vehicles. The results have also included information from simplified diaries kept by children aged 7-15 years.

In most years, surveys reported dried milk in its reconstituted liquid equivalent volume. All other dry or concentrated beverages (chocolate drinks, coffee beans and tea leaves, powders or essences) were reported as purchased. We adjusted these systematically across the surveys so the reconstituted liquid equivalents are reported for all beverages for the prices paid. This included Ribena and other beverage concentrates that require different reconstitution formulas. Appendix 1 shows which beverages belong to each group, and Appendix 2 shows the ratios of diluent:powder used to adjust non-liquid beverages to their liquid equivalents. The main difference between analysis of beverages in the dietary intake and food expenditure surveys is that we were able to create separate categories for sweetened and unsweetened tea and coffee for the dietary intake data. 
Table 1. Beverage categories from Great Britain dietary intake data sources*

\begin{tabular}{|c|c|}
\hline Beverage group used & Definition used and examples \\
\hline High-fat milk & $\begin{array}{l}>2 \% \text { milk fat } \\
\text { Whole milk, 'UHT' or sterilised liquid milk; condensed milk, evaporated milk, } \\
\text { infant milk, powdered milk, non-skimmed milk, cream }\end{array}$ \\
\hline Reduced-fat milk & $\begin{array}{l}\leq 2 \% \text { milk fat } \\
\text { Skimmed milk, fully skimmed milk, semi- and other skimmed milk, almond, } \\
\text { soya, rice, hemp and other milks }\end{array}$ \\
\hline Sweetened dairy & $\begin{array}{l}\text { Dairy beverages with added sugars } \\
\text { Yogurt drinks, probiotics, milkshakes, cocoa with milk, Horlicks, Ovaltine }\end{array}$ \\
\hline Alcohol & Any alcoholic content \\
\hline Spirits/liqueurs & Spirits, liqueurs \\
\hline Wines & Wine, fortified wines \\
\hline Beer/cider/alcopops & $\begin{array}{l}\text { Low-alcohol beers, lagers and ciders; beers; lager and continental beers; } \\
\text { ciders and perries; alcopops }\end{array}$ \\
\hline Soda and fruit drinks with added sugar & $\begin{array}{l}\text { Sugar-sweetened soft drinks and fruit drinks ( }<100 \% \text { juice }) \\
\text { Regular soft drinks, fruit-flavoured drinks, nectars, Ribena }\end{array}$ \\
\hline Low-nutritive 'diet'-sweetened drinks & $\begin{array}{l}\text { Diet or low-energy substitute sweetened drinks } \\
\text { Low-energy soft drinks, low-energy fruit drinks, diet sweetened tea/coffee drinks }\end{array}$ \\
\hline Juices & $\begin{array}{l}100 \% \text { juice } \\
\quad \text { Fruit juice, vegetable juice }\end{array}$ \\
\hline Unsweetened coffee/tea & Coffee or tea consumed without any added sweeteners or dairy \\
\hline Sweetened coffee & Coffee consumed with added sweeteners (low-energy, diet, artificial or regular) or dairy \\
\hline Sweetened tea & Tea consumed with added sweeteners (low-energy, diet, artificial or regular) or dairy \\
\hline Other energy & $\begin{array}{l}\text { Other energy drinks not included above } \\
\text { Cacao Power, drinking chocolate and instant chocolate drinks consumed } \\
\text { without dairy }\end{array}$ \\
\hline Water as a beverage & $\begin{array}{l}\text { Zero energy waters } \\
\quad \text { Tap water (filtered or unfiltered), bottled water, mineral water }\end{array}$ \\
\hline
\end{tabular}

UHT, ultra-high temperature.

* Dietary data used: Dietary and Nutritional Survey of British Adults, 1986-7; 1992 National Diet, Nutrition and Dental Survey of Children (1.5-4.5 years); 1997 National Diet and Nutrition Survey (NDNS) of Young People (4-18 years); 2000-1 NDNS of Adults (19-64 years); 2008-9 NDNS Rolling Programme of adults and children ( $\geq 1.5$ years).

There were some significant differences in how beverage data were recorded for the most recent surveys. Takeout coffee and tea were added in 2007 as was the separation of vegetable purées into juices and purées; water purchases were not collected until 1985, and alcohol purchases were not added until 1992. Similarly, sugar-sweetened milk was only added in 2008.

For studying the associations between changes in the prices households faced on their beverage purchases, we needed to have a beverage price for all the beverages studied for each household at the relevant time period of the diary collection. However, prices are reported only for the households which purchase the items, and there were too many differences between the NFS and the EFS that affected expenditure and our ability to create price measures in a consistent manner. In addition, the EFS had less than $1 \%$ missing measures for the demographic measures used: household size and numbers of adult males and females and children, employment status and education levels for adults in the household, family income per week, and recipient of income support, while the NFS had up to $39 \%$ missing values for some of these measures for certain years. Consequently, we only use the EFS data for imputing prices to conduct price-related analyses, given that they would be more reflective of current beverage purchase trends and behaviours and thus more appropriate for simulating a response to potential price shifts. To impute prices for the EFS, we divided expenditure over volume purchased for each beverage type among those who reported purchasing that beverage within a geographical area. We then assumed that this average price was the price that all respondents within the same geographical area were exposed to. In this way, all respondents had measures of an average price for each beverage, regardless of whether they purchased beverages or not. This is the standard method economists have used for decades as the most valid method for deriving prices when utilising expenditure data for price studies ${ }^{(36)}$.

\section{Statistical procedures}

To describe nationally representative beverage dietary intake and purchases ( $\mathrm{g}$ or $\mathrm{ml}$ and energy) using the various national dietary intake data and food expenditure surveys, surveyweighted means were calculated. Energy from non-beverage sources was also calculated from each survey. We conducted $t$ tests to analyse differences in energy consumed from and volume purchased for beverages and the various types of beverages over time. A $P$ value $<0.01$ was considered significant.

For the analysis of income and price elasticities, we selected the most recent as well as the earliest food purchase survey data for which we had reliable price and income data (i.e. EFS 2001 and 2007). Separate estimations were done for two separate but related decisions: the decision to purchase, and the conditional decision of the amount to purchase. This follows standard statistical procedures of eliminating biases when examining outcomes such as purchase of milk or soft drinks where there are large proportions of zero purchasers ${ }^{(37)}$ by using a survey-weighted two-part model. Purchase distribution can be skewed because some people do not purchase 
certain foods. Thus, researchers recommend using two-part models to analyse either food purchase or dietary intake behaviours $^{(37)}$. The two-part models are also useful in predicting actual outcomes based on observed data.

The analysis examined separately two cross-sections to estimate the price effects at specific years. The assumption is that with two nationally representative samples, the mean statistics based on the pooled sample of households represents the 'average' household in each of the cross-sections. It would have been preferable to conduct time-series analyses, which would have allowed for error correlations over time across the same households. However, given the cross-sectional nature of the data available, this was not possible. The twopart model included a survey-weighted probit model using maximum-likelihood estimation in the first part to estimate the probability of purchasing any of the particular beverage of interest. The second part is a log-linear survey-weighted ordinary least-squares regression model on only the subsample of those who did purchase a particular beverage of interest. The two parts have the same specifications. These two parts were estimated separately before we derived the unconditional elasticities and bootstrapped standard errors.

Own-price and cross-price effects on the volume $(\mathrm{ml})$ of purchase of each beverage were calculated. The former is defined as the change in quantity in demand that occurs in response to a percentage change in price. This should be negative. Cross-price effect of demand is the change in quantity demanded for the first good that occurs in response to a percentage change in the price of a second good. Goods with positive cross-price effects are considered substitutes and those with negative cross-price effects are considered complements. Examples of substitutes are coffee and tea, while coffee and milk can be complements. Stata version 11.0 (Stata Corp.) was used in all analyses ${ }^{(38)}$.

Ideally, it would be useful to study the effects of taxation based on added sugar content in beverages. However, this would require knowing the 'added sugar' of all beverages purchased or consumed, which does not exist even if one were to use commercial databases linked with nutrition facts panel data since only total sugar is reported. Therefore, we rely on a simplistic approach of looking at price effects on certain sets of beverages that are known to have high or low added sugar content. For ease of interpretation, we derived simulations on the changes in the amount of beverages bought that is associated with a 10 and $20 \%$ increase in the price of each beverage. Our estimates are point estimates based on current purchase levels and assume linearity.

\section{Results}

\section{Beverage intake patterns and trends}

In the most recent (2008-9) NDNS Rolling Programme, we can observe the different beverage consumption patterns by age groups. Fig. 1(a) shows that preschoolers (aged 2-6 years) had $68 \%$ of their beverage energy coming from dairy sources (reduced-fat milk, high-fat milk and sweetened dairy). The proportion gets progressively lower with the older age groups, and for adults (19-64 years), only $10 \%$ of energy from beverages are from dairy sources. Fig. 1(b) shows that sugar-sweetened beverage (soda, fruit drinks and sweetened coffee and tea) intake is the highest both in absolute and relative terms $(548 \mathrm{~kJ}$ or $41 \%$ of energy from beverages) among adolescents (13-18 years), and is also large for adults $(431 \mathrm{~kJ})$ but much lower among children and preschoolers. In addition, energy from alcohol contributes to $16 \%$ of energy intake from beverages among adolescents, and $43 \%$ of energy from beverages among adults.

There have been limited surveys on dietary intake for all age groups before the new 2008-9 survey. For the years of data available for select age groups, we present the per capita energy consumption from dairy and non-dairy beverages. Additional details are available in Tables A1 and A2 of Appendix 3, which present the per capita consumption, the proportion of individuals who consume a particular beverage (over a $4 \mathrm{~d}$ basis) and the average daily amount consumed among consumers. These are in terms of energy contribution and total volume consumed. We also present the sample sizes for each of the surveys by age groups.

Young children aged $1.5-4.5$ years. For the purposes of comparison across the available data in 1992 and 2008-9, we looked at 1.5-4.5-year-old children. We found that the proportion of young children consuming high-fat milk, sweetened dairy, sodas/fruit drinks and sweetened tea fell significantly, but the percentage who consumed fruit juices rose significantly (from 39 to $58 \%$ ). However, from a per capita energy consumption standpoint, only energy from soda/fruit drinks, sweetened tea and other energy drinks fell significantly. This means that even though fewer young children are consuming any high-fat milk and sweetened dairy, those who are consuming these beverages are getting more energy from these sources, indicative of increasing disparities in intake (see Table A1 of Appendix 3).

Children and adolescents aged $4-18$ years. Milk (high fat plus low fat) intake overall declined slightly from 1997 and 2008-9 for preschoolers, children and adolescents, due to the decline of high-fat milk concurrent with a much smaller increase in reduced-fat milk (see Fig. 2(a)). Sweetened dairy, however, has emerged to almost equal reduced-fat milk in per capita consumption levels across all these age groups.

In 2008-9, energy from beverages represented about $14 \%$ of energy intake for all British children aged 4-18 years with the bulk of energy coming now from sugary beverages such as soda, fruit drinks, juices and sweetened dairy (see Table A1 of Appendix 3). The most commonly consumed beverage for this age group continues to be sugar-sweetened beverages, with sugar-sweetened beverage intake in the 2008-9 period being especially high among adolescents. The proportions consuming any juices rose significantly from 44 to $53 \%$, and sweetened dairy is now consumed by nearly a third of children aged 4-18 years (Fig. 2(b)).

Adults aged 19 years and older. In 2008-9, energy intake from beverages represented about $18 \%$ of energy intake for all British adults aged 19-64 years with the bulk of energy coming now from alcohol and sugar-sweetened beverages such as soda, fruit drinks, sweetened coffee, tea and juices 
Since 1986, there have been three points to measure dietary intake of beverages by adults. During this period, British adults' overall proportion of energy from beverages has changed very little, but there are some shifts in the sources of energy from beverages. Fig. 3(a) describes changes in the consumption of dairy beverages, which while continuing to contribute to $10-11 \%$ of energy from beverages, has significantly shifted away from high-fat milk towards reduced-fat milk. Energy from sweetened dairy has also declined, particularly between 1986-7 and 2000-1.

For the average adult, SSB increased gradually from $113 \mathrm{~kJ} / \mathrm{d}$ in $1986-7$ to $209 \mathrm{~kJ} / \mathrm{d}$ in $2008-9$, as did alcohol, which by 2008-9 accounted for nearly half of the energy from beverages. Wine increased slightly but beer remains the single largest source of energy from beverages and represents about two-thirds of energy from alcohol (see Table A2 of Appendix 3). Meanwhile, sweetened tea and coffee and other energycontaining drinks declined markedly (Fig. 3(b)). Much of these noted changes may be due to the fact that since 1986-7, the percentage of British adults consuming high-fat milk, sweetened tea and coffee fell significantly, while the percentage who consumed reduced-fat milk, low-nutritive (diet) sweetened drinks and juices rose. In addition, we note that
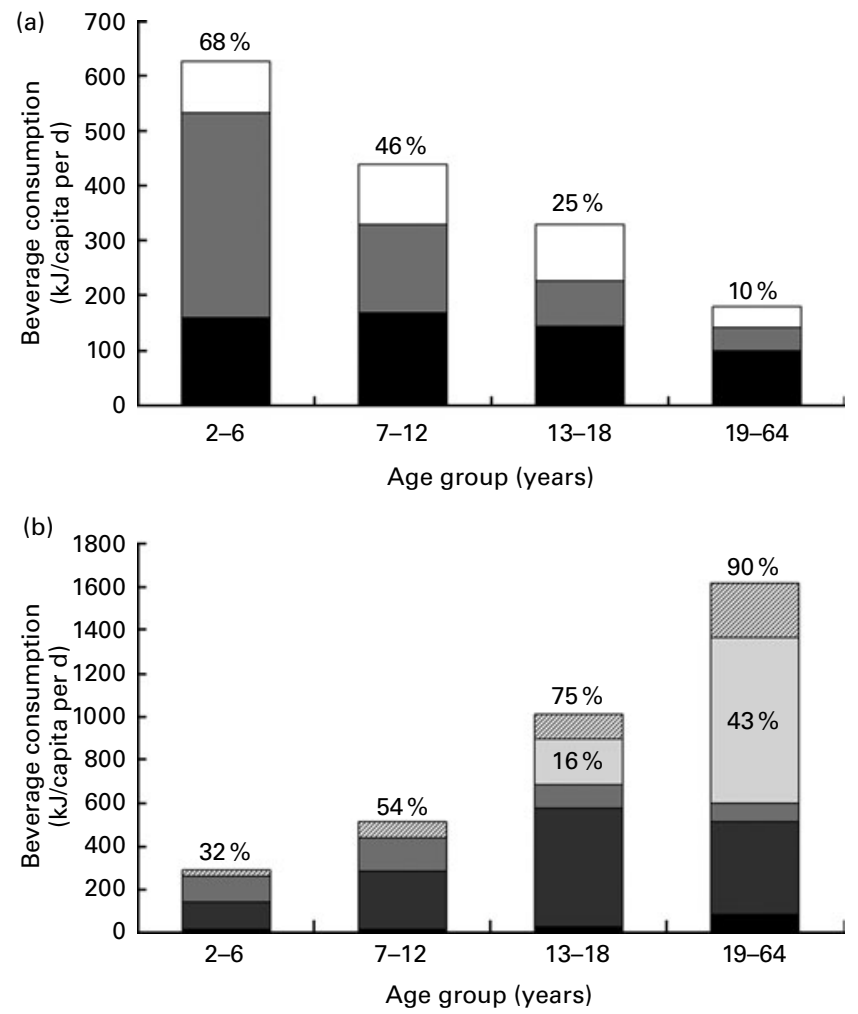

Fig. 1. Daily per capita (a) dairy and (b) non-dairy energy beverage consumption in the UK in 2008-9, by age groups. Results are weighted to be nationally representative. Percentage reflects the contributing source of energy from all beverages. $\square$, Sweetened dairy; $\square$, high-fat milk; $\mathbf{\square}$ reduced-fat milk; $\square$, other energy; $\square$, alcohol; $\square$, juices; $\square$, soft drinks, juice drinks and sweetened coffee/tea; $\mathbf{\square}$, diet drinks and unsweetened coffee/tea. Source: National Diet and Nutrition Survey Rolling Programme, 2008-9 ( $n$ 995), 4 d diet recall.

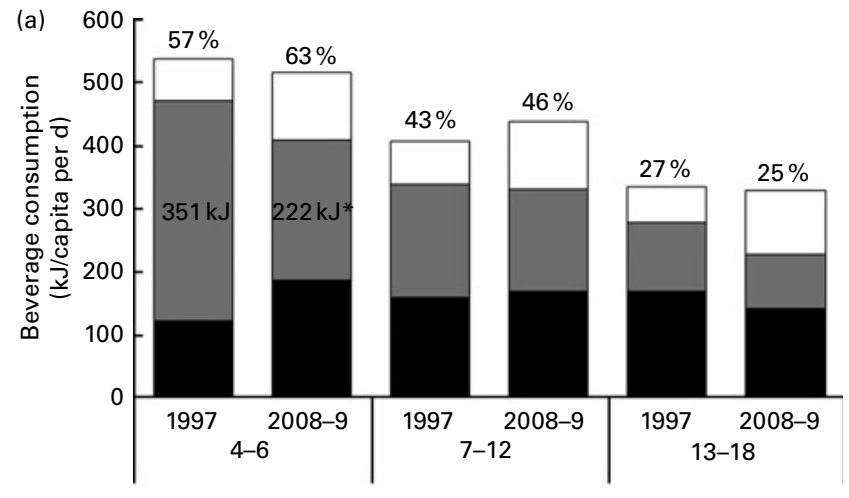

Survey year and age group (years)

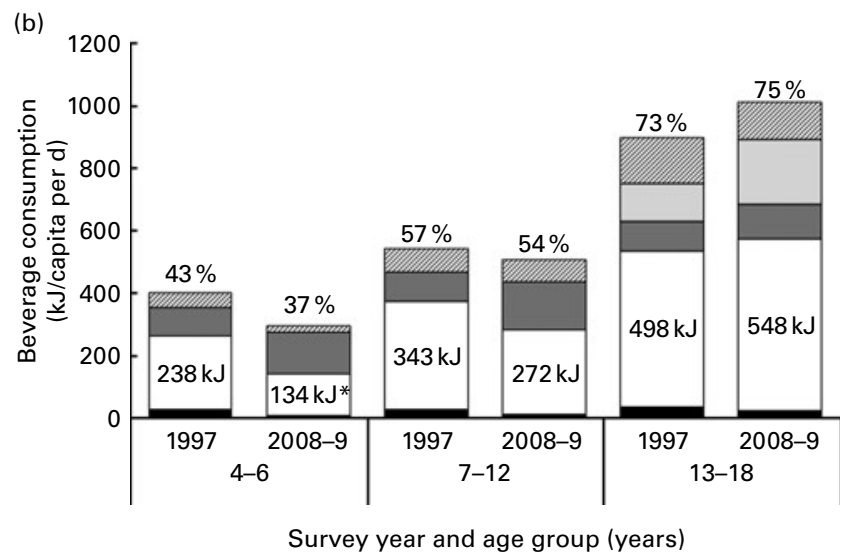

Fig. 2. Daily per capita (a) dairy and (b) non-dairy beverage consumption in the UK among children aged 4-18 years, 1997 v. 2008-9. Results are weighted to be nationally representative where weights were available. Percentage reflects the contributing source of energy from all beverages. $\square$, Sweetened dairy; $\square$, high-fat milk; $\square$, reduced-fat milk; 四, other energy; $\square$, alcohol; $\square$, juices; $\square$, soft drinks, juice drinks and sweetened coffee/tea; 口, diet drinks and unsweetened coffee/tea. *Values were significantly different between 1997 and 2008-9 $(P<0.01)$. Sources: National Diet and Nutrition Survey of Young People (4-18 years), 1997 ( $n$ 1798), $7 \mathrm{~d}$ recall bootstrap sampled to a $4 \mathrm{~d}$ diet recall; National Diet and Nutrition Survey Rolling Programme, 2008-9 ( $n$ 462), 4 d diet recall.

the increase in energy from juice was due to both increases in the percentage of consumers and the amount consumed per person. Adults, in particular, had a large increase in the consumption of low-nutritive (diet) sweetened beverages from $17 \mathrm{ml} / \mathrm{d}$ in $1986-7$ to $102 \mathrm{ml} / \mathrm{d}$ in 2008-9 (see Table A2 of Appendix 3).

Water's role in British beverage patterns. The volume of total water intake per capita across all age groups has increased over time. These differences are large and statistically significant (Fig. 4). From these cross-sectional years of data, about $23-32 \%$ of water intake comes from food sources, and the remainder comes from beverages. Water as a beverage increased across all age groups in the most recent survey, which may be due to greater efforts to measure water consumption in the more recent surveys. Still, it is important to note that the surveys may not provide reliable data on tap or unbottled water intake ${ }^{(23,24)}$. 

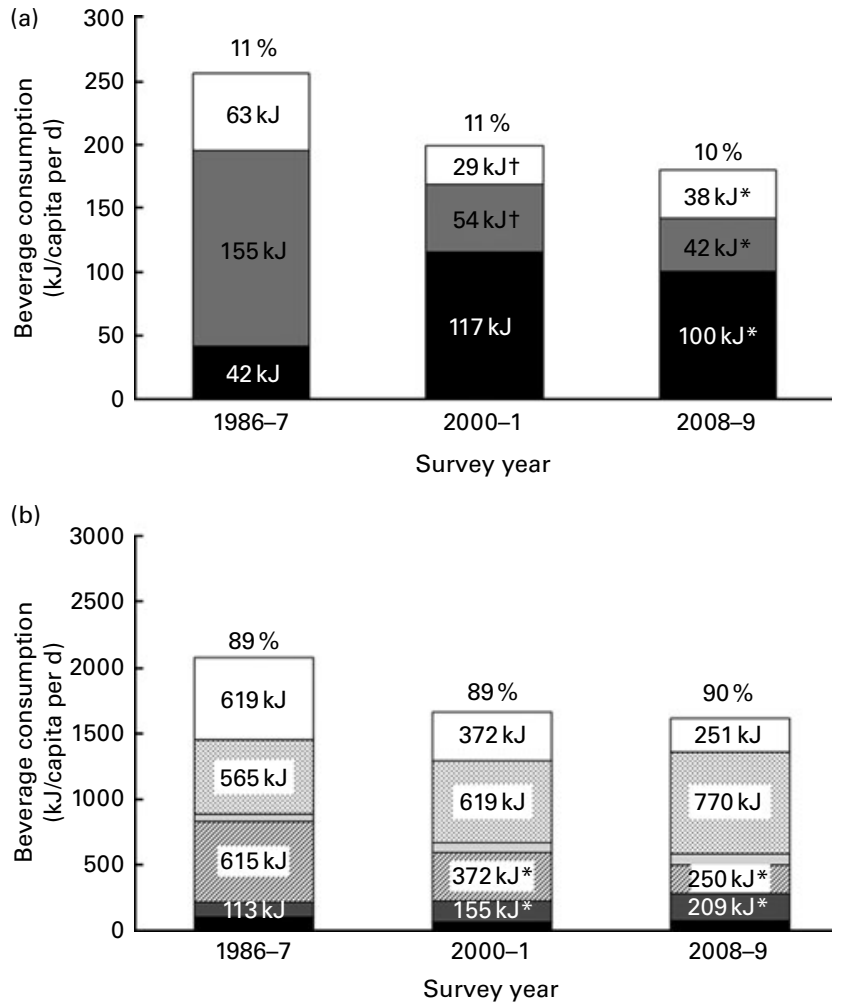

Fig. 3. Trends in daily per capita (a) dairy and (b) non-dairy energy beverage consumption among adults (19-64 years) in the UK, 1986-7, 2000-1, $2008-9$. Results are weighted to be nationally representative where weights were available. Percentage reflects the contributing source of energy from all beverages. $\square$, Sweetened dairy; $\square$, high-fat milk; $\square$, reduced-fat milk; $\square$, other energy; $⿴ 囗$, alcohol; $\square$, juices; 四, sweetened coffee/tea; $\square$, soda/ juice drinks; diet drinks and unsweetened coffee/tea. *Values were significantly different between 1986-7 and 2008-9 $(P<0.01)$; †Values were significantly different between $2000-1$ and 2008-9 $(P<0.01)$. Sources: Dietary and Nutritional Survey of British Adults, 1986-7 ( $n$ 2030), $7 \mathrm{~d}$ diet recall bootstrap sampled to use only a $4 \mathrm{~d}$ diet recall; National Diet and Nutrition Survey, 2000-1 ( $n$ 1724), $7 \mathrm{~d}$ diet recall bootstrap sampled to use only a $4 \mathrm{~d}$ diet recall; National Diet and Nutrition Survey Rolling Programme, 2008-9 ( $n$ 434), 4 d diet recall.

\section{Long-term trends in household per capita purchases}

The household expenditure data collected from British families demonstrate changes in purchases over the 1975-7 period. Fig. 5 highlights major shifts while Table A3 of Appendix 3 provides detailed information. The major trends over these three decades include a reduction in purchase of tea, no change in coffee, a decline in overall purchases of milk with a shift towards more reduced-fat milk, and a slight decline in sweetened dairy (e.g. yogurt drinks, hot chocolate), a large increase in SSB (soda and fruit drinks), low-nutritive (diet) sweetened beverages and fruit juice.

These results are provided only in $\mathrm{ml}$ of weekly purchase after adjusting for the number of people in each household. These data represent purchases during a limited time period and do not account for wastage. Our inability to separate coffee and tea purchases into unsweetened and sweetened categories does not allow any understanding of the health effects of shifts in tea and coffee purchases. However, the total increase in the purchases of beverages containing sugar - SSB (soda and fruit drinks) and fruit juices - is clear.

\section{Price effects}

Water, chocolate drinks and vegetable juice purchases were made by about 20,10 and $1 \%$ of the households, respectively, and we do not report the effects of prices on these outcomes (SW Ng and BP Popkin, unpublished results). We also exclude alcohol, though over $50 \%$ of households purchased this. For all the other beverages, the proportion of households that purchased the items ranged from 30 to $75 \%$.

Analyses of the two cross-sectional datasets from 2001 and 2007 provide the estimated own-price effects, defined as the $\mathrm{ml}$ change in amount purchased per capita per week, related to a 10 and $20 \%$ increase in price (Table 2). These are the estimates of the effect of changes in the price of SSB from a tax or removal of a subsidy on SSB on beverage purchases. SSB are fairly price responsive, with a $10 \%$ increase in the price of SSB being associated with a $50-53 \mathrm{ml} /$ capita per week (or about $7.5 \mathrm{ml} /$ capita per d) lower purchase. Increasing elasticities for juice and reduced-fat milk over time suggest a shift towards reduced-fat milk as the commodity of choice and also greater availability of different varieties of milks (e.g. soya, rice, almond) and juice such that households have become more price sensitive to these beverages. Also, consumers are consistently price responsive to increases in the prices of tea, although less so over time.

Using the 2007 EFS data, we estimated the associations between a 10 and $20 \%$ increase in the price of some of these beverages and the weekly purchase (in $\mathrm{ml}$ ) of other beverages (Table 3 ). The values along the diagonals are the ownprice effects, which are the same as reported in Table $2 \mathrm{~B}$ for the weekly purchase in $\mathrm{ml}$ for the average household member on a per capita basis. The values in the off-diagonals are the cross-price effects. We find that raising the price of SSB

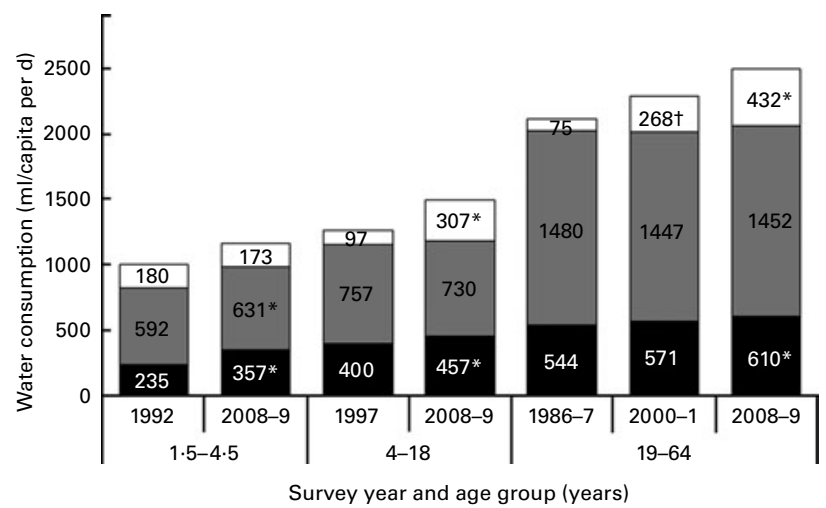

Fig. 4. Daily per capita water consumption in the UK in 2008-9, by age groups. Results are weighted to be nationally representative where weights were available. $\square$, Water as a beverage; $\square$, water in other beverages; water in food. *Values were significantly different between earliest year and 2008-9 $(P<0.01)$. †Values were significantly different between 1986-7 and 2000-1 $(P<0.01)$. Sources: National Diet and Nutrition Survey of Young People (4-18 years), 1997 ( $n$ 1798), $7 \mathrm{~d}$ recall bootstrap sampled to a $4 \mathrm{~d}$ diet recall; National Diet and Nutrition Survey Rolling Programme, 2008-9 (n 462), $4 \mathrm{~d}$ diet recall. 


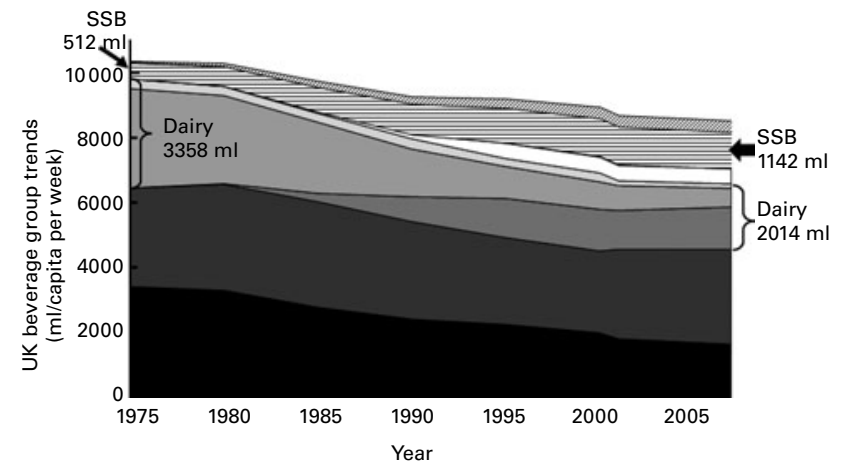

Fig. 5. UK beverage group trends ( $\mathrm{ml}$ purchased per person per week), 1975-2007. $\square$, Tea; $\square$, reduced-fat milk; $\square$, sweetened diary; $\square$, sugar sweetened beverages; $\square$, coffee; $\square$, high-fat milk; 目, diet drinks; 勿, fruit juices. SSB, sugar-sweetened beverages. Source: UK household expenditures and consumption from the 1975-2000 Family Expenditure Survey and the 2001-7 Expenditure and Food Survey.

had no significant effect on the consumption of other beverages, and the demand for low-nutritive (diet) sweetened beverages is separate from that for SSB (i.e. they are not substitutes). In contrast, there is strong substitutions among the high- and reduced-fat milks, as we find that a $10 \%$ increase in the price of high-fat milk is associated with an increase in the purchase of reduced-fat milk by $48 \mathrm{ml}$ /capita per week $(7 \mathrm{ml} /$ capita per $\mathrm{d}$ ) and a decrease in high-fat milk purchases by $35 \mathrm{ml} /$ capita per week $(5 \mathrm{ml} /$ capita per $\mathrm{d})$.

\section{Discussion}

In 2008-9, beverages accounted for 21, 14 and $18 \%$ of energy per $\mathrm{d}$ for children aged $1 \cdot 5-18$ and $4-18$ years, and adults (19-64 years), respectively. Since the 1990s, the most important shifts have been a reduction of consumption of high-fat milk, particularly among preschoolers, children and adolescents with a shift towards sodas, fruit drinks, juices and sweetened dairy. Among adults, consumption of dairy, sweetened tea and coffee and other energy-containing drinks fell, but alcohol (particularly beer) and juice rose. Furthermore, the total volume of water consumed increased.

Data are limited but patterns of beverage consumption in British adolescents appear to mirror those of adolescents across other European countries ${ }^{(39)}$. In comparison with the USA, Mexico and other countries with published beverage consumption data, the British beverage consumption pattern has not changed as markedly ${ }^{(27,40)}$. While energy from beverages has not shifted markedly overall during the past decade in Britain, energy intake from beverages, especially $\mathrm{SSB}$, remains a significant contributor to total energy intake. Given that the population-level energy imbalance in the UK over the last 10 years, estimated very recently by a Department of Health Expert Group, has just been 67 or $100 \mathrm{~kJ} / \mathrm{d}$ for the 90th percentile of weight gain ${ }^{(41)}$, encouraging the replacement of SSB and high-fat milk with less energy-dense beverages is one potential public health target.

To understand the implications of taxation as an option for shifting beverage consumption patterns, the present study explored taxation of SSB and high-fat milk, among other products. The findings for a $10 \%$ price increase were quite comparable with the effect found in the USA and Mexico ${ }^{(40,42-44)}$. Increasing the price of SSB by just $10 \%$ is associated with a reduction of $7.5 \mathrm{ml} /$ capita per d based on 2007 data. Interestingly, there is a clear substitution between high-fat and reduced-fat milk whereby a $10 \%$ price increase of high-fat milk is associated with a decline in purchase by $5 \mathrm{ml} /$ capita per $\mathrm{d}$ and an increase in the purchase of reduced-fat milk by $7 \mathrm{ml} /$ capita per $\mathrm{d}$. We consider the potential implications on beverage purchases of these price changes. In 2007, the British population was about 60769000 . Data from the British soft drink industry ${ }^{(45)}$ indicate total annual soft drink (including bottled water, sports and energy drinks, fruit juices, smoothies, and SSB) volume sales of 14060 million litres, or 231 litres/ capita, of which only 65\% (or 151 litres/capita per year) apply to our categorisation of SSB. Our estimate of $7.5 \mathrm{ml} /$ capita per $\mathrm{d}$ reduction in SSB purchase is equivalent to $2 \cdot 8$ litres/capita per year, or about $1.9 \%$ of the total British SSB (based on our definition) volume. Given that change in SSB volume sales over the last 5 years has ranged from $-1 \cdot 1$ to $+3.3 \%$ per year ${ }^{(45)}$, this is not an insignificant finding. Meanwhile, a $10 \%$ increase in the price of high-fat milk is associated with a decrease of about $6 \%$ of the total British high-fat milk sales, and an increase of nearly $4 \%$ of the total British reduced-fat milk sales (based on applying the estimates from the ESF 2007 data). We do not extend the present findings to estimate potential changes in beverage intake or health outcomes since there are differences between what is purchased and consumed (e.g. people might be consuming fruit juices that are freshly squeezed rather than packaged from the store; people may be buying milk and adding it to their coffee or tea, or using it for cooking/baking). However, this analysis suggests the potential for taxation or other methods of shifting relative costs of these beverages as a way to change beverage choices in Great Britain, which may support public health goals.

Of course, the present paper focuses only on beverages, so there are other important foods that might be affected by beverage prices that we cannot address here. In addition, we do not address the role of price changes in alcohol $^{(46)}$, a beverage whose role in obesity and cardiometabolic health is quite complex ${ }^{(47,48)}$. Ideally, we would have liked to study how taxation based on added sugar content or fat content would affect beverage purchase and/or intake. However, that would require detailed measurements of each beverage purchased/consumed along with the added sugar content of each beverage product, which currently are not even reported on nutrition facts panels and do not exist in any country. Therefore, we have simply looked at SSB as a beverage category that is known to have significant added sugar content, and milks by fat content.

In considering taxation based on added sugar, it is not clear what proportion of this tax might be absorbed by producers. However, it is likely as it was with alcohol and tobacco taxation that all (or a large proportion of) taxes are passed on through higher prices and reduced purchases as we show $^{(49-51)}$. Interestingly, in the agricultural area, recent subsidies on food are often not passed on either to producers or 
Table 2. Effects of a 10 and $20 \%$ price increase on the volume $(\mathrm{ml})$ of weekly purchases of beverages per capita†

\begin{tabular}{|c|c|c|c|c|c|c|}
\hline & \multicolumn{3}{|c|}{$10 \%$ price increase } & \multicolumn{3}{|c|}{$20 \%$ price increase } \\
\hline & $\begin{array}{l}\text { With income } \\
\text { support }\end{array}$ & $\begin{array}{l}\text { Without income } \\
\text { support }\end{array}$ & $\begin{array}{c}\text { Average } \\
\text { UK household }\end{array}$ & $\begin{array}{l}\text { With income } \\
\text { support }\end{array}$ & $\begin{array}{l}\text { Without income } \\
\text { support }\end{array}$ & $\begin{array}{c}\text { Average } \\
\text { UK household }\end{array}$ \\
\hline \multicolumn{7}{|l|}{ A. 2001 (7411 households) } \\
\hline Coffee & $-54^{\star}$ & $-42^{\star}$ & $-43^{*}$ & $-107^{\star}$ & $-86^{\star}$ & $-89^{\star}$ \\
\hline Tea & $-241^{\star}$ & $-61^{\star}$ & $-84^{\star}$ & $-458^{*}$ & $-121^{*}$ & $-162^{*}$ \\
\hline Reduced-fat milk & $-53^{\star}$ & $-43^{\star}$ & $-45^{\star}$ & $-106^{\star}$ & $-84^{\star}$ & $-88^{*}$ \\
\hline High-fat milk & $-80^{\star}$ & $-41^{\star}$ & $-46^{\star}$ & $-151^{\star}$ & $-79^{\star}$ & $-89^{\star}$ \\
\hline Low-nutritive 'diet'-sweetened beverages & -46 & -26 & -28 & -86 & -50 & -53 \\
\hline Sugar-sweetened beverages & $-72^{*}$ & $-47^{\star}$ & $-50^{\star}$ & $-137^{\star}$ & $-92^{*}$ & $-98^{\star}$ \\
\hline Fruit juice & -24 & -13 & -14 & -46 & -25 & -28 \\
\hline 2001 households (\%) & 12 & 88 & 100 & 12 & 88 & 100 \\
\hline \multicolumn{7}{|l|}{ B. 2007 (6071 households) $\ddagger$} \\
\hline Coffee & -33 & -30 & -30 & -65 & -59 & -60 \\
\hline Tea & $-61^{\star}$ & $-48^{\star}$ & $-49^{\star}$ & $-121^{*}$ & $-94^{\star}$ & $-95^{\star}$ \\
\hline Reduced-fat milk & $-68^{\star}$ & $-72^{*}$ & $-72^{*}$ & $-132^{*}$ & $-140^{*}$ & $-140^{\star}$ \\
\hline High-fat milk & $-41^{*}$ & $-35^{\star}$ & $-35^{\star}$ & $-78^{*}$ & $-68^{\star}$ & $-69^{\star}$ \\
\hline Low-nutritive 'diet'-sweetened beverages & -22 & -23 & -22 & -42 & -44 & -44 \\
\hline Sugar-sweetened beverages & $-62^{\star}$ & $-53^{*}$ & $-53^{\star}$ & $-121^{*}$ & $-103^{*}$ & $-104^{\star}$ \\
\hline Fruit juice & -12 & $-19^{\star}$ & $-19^{\star}$ & $-23^{\star}$ & $-37^{\star}$ & $-36^{\star}$ \\
\hline 2007 households (\%) & 6 & 94 & 100 & 6 & 94 & 100 \\
\hline
\end{tabular}

Source: The UK Data Archive National Food Surveys 2001 and 2007.

Note: Results are weighted to be nationally representative and are in terms of $\mathrm{ml} / \mathrm{capita}$ per week.

*Values were significantly different at the $5 \%$ level $(P<0.05)$.

TThese point elasticities are based on a two-part model that first estimates the effects of prices while controlling for key sociodemographic measures. These include: family income, whether a person in the household has full-time employment, the highest education of members of the household, the total household size, the number of adult males and females and children in the household, the price per $100 \mathrm{~g}$ of each beverage. Prices of other beverages are included in each model. The sample is stratified by whether the household had income support or not.

$\ddagger \ln 2007$, the sample of households with income support was very small $(<6 \%)$. 
Table 3. Effects of a 10 and $20 \%$ price increase of select beverages on the per capita weekly purchases of other beverages for $2007 \dagger \neq$

\begin{tabular}{|c|c|c|c|c|c|}
\hline & \multicolumn{5}{|c|}{ Change in per capita weekly purchases (ml) } \\
\hline & Reduced-fat milk & High-fat milk & Low-nutritive 'diet' sweetened & SSB & Fruit juice \\
\hline \multicolumn{6}{|l|}{$10 \%$ increase in the price of } \\
\hline Reduced-fat milk & $-72^{*}$ & $15^{*}$ & $-25^{\star}$ & -2 & 5 \\
\hline High-fat milk & $48^{\star}$ & $-35^{\star}$ & 7 & -5 & 5 \\
\hline Low-nutritive 'diet'-sweetened drinks & -9 & -1 & -22 & 11 & -1 \\
\hline SSB & -4 & 0 & 3 & $-53^{*}$ & 0 \\
\hline Fruit juice & -1 & 1 & $-4^{*}$ & -7 & $-19^{*}$ \\
\hline \multicolumn{6}{|l|}{$20 \%$ increase in the price of } \\
\hline Reduced-fat milk & $-140^{\star}$ & $31^{*}$ & $-49^{*}$ & -4 & 10 \\
\hline High-fat milk & $96^{*}$ & $-69^{\star}$ & 15 & -10 & 11 \\
\hline Low-nutritive 'diet'-sweetened drinks & -18 & -1 & -44 & 23 & -2 \\
\hline SSB & -9 & 0 & 6 & $-104^{*}$ & 1 \\
\hline Fruit juice & -2 & 2 & $-9^{*}$ & -14 & $-36^{\star}$ \\
\hline
\end{tabular}

SSB, sugar-sweetened beverages.

Source: The UK Data Archive National Food Survey 2007.

Note: Results are weighted to be nationally representative.

*Values were significantly different at the $5 \%$ level $(P<0.05)$.

†These point elasticities are based on a two-part model that first estimates the effects of prices while controlling for key sociodemographic measures. These include: family income, whether a person in the household has full-time employment, the highest education of members of the household, the total household size, the number of adult males and females and children in the household, the price per $100 \mathrm{~g}$ of each beverage. Prices of other beverages are included in each model.

$\ddagger$ In 2007 , the sample of households with income support was very small $(<6 \%)$

consumers but rather absorbed by agribusiness middlemen ${ }^{(52,53)}$. Another consideration that we have not studied here is the potential of using revenue from taxation of less healthy foods and beverages to support direct point-ofpurchase subsidies on healthier foods such as fruits and vegetables, which has been shown to influence consumption in an intervention study ${ }^{(54)}$. The debate around taxing certain foods or beverages can be contentious, particularly in countries such as the USA ${ }^{(55)}$, making price simulation exercises, like what we have done here, critical in providing the scientific basis for any arguments on either side of the issue.

This is not to say that there are no limitations to the present study. One limitation is the basic issue of under-measurement and limitations in the collection of accurate $24 \mathrm{~h}$ recall data, in particular less desirable foods high in fat or sugar ${ }^{(56)}$. Comparison of self-reported intakes in the NDNS with measured energy expenditure provides clear evidence of under-reporting of energy intake, highlighted in past studies suggesting that there is a secular trend towards greater under-reporting ${ }^{(57,58)}$. A similar analysis has not been performed on the present NDNS data, as they represent only the first year in a rolling programme. Further measures of energy expenditure using doubly labelled water have been conducted in year 3, but have yet been reported. However, preliminary suggestions are that under-reporting is of similar magnitude in the recent survey to that reported in an earlier study ${ }^{(58)}$. This would mean that our measurement of trends for SSB intake and other sugary or high-energy beverages might actually be understated $^{(58-62)}$.

In addition, there are gaps in the measurement of selected beverages - an issue that also exists in US diet and expenditure data. We compared the patterns with British Soft Drinks Association data. Sports and energy drinks do not appear to be captured in these surveys. In a related report by the British Soft Drinks Association, a marked increase in the consumption of energy drinks is shown, to about 8.3 litres/person per year $^{(45)}$. We also could not find any category for flavoured waters, many of which are sweetened. Moreover, the NSF and ESF are based on 1- and 2-week food and beverage expenditure diaries, which do not fully capture the consumption patterns of households over the course of the year and are simply snapshots. As such, consumption of some of these beverages may seem lower that is estimated from propriety data (e.g. The Nielson Company, Symphony IRI Group) that track household purchases over longer periods of time and across seasons. The same is true, of course, for the dietary intake measures. There would be great potential for UK scholars to utilise the TNS Kantar sales and purchase data or the Nielsen data for the UK to study tax issues as has been done in the USA ${ }^{(45)}$. As with the publicly available dietary intake data, these data provide benefits in sample size and precise prices but lack representativeness, and suffer from other data collection issues ${ }^{(63-65)}$.

In summary, this is a comprehensive study of trends in overall beverage intake patterns in Britain. We utilise sophisticated methods to ensure comparability of trends between all surveys. A marked decline in the intake of dairy beverages with a shift towards sweetened milk is one major finding. A second is the increase in the consumption of all sugarsweetened beverages across all age groups along with high alcohol intake among British adults. Modelling suggests that higher prices for high-fat milk and SSB are associated with a reduction in their purchase while increasing purchases of healthier beverages (e.g. reduced-fat milk).

\section{Acknowledgements}

The present study was supported by funding from the University of North Carolina and the Medical Research Council, UK. We thank Ms Ashley Olson from the MRC-Human Nutrition 
Research for her help in guiding our efforts to create a bootstrapped sample for comparisons of the dietary data over the various years. Also, we thank Phil Bardsley and Rick O'Hara for programming assistance, Tom Swasey for graphic assistance, and France Dancy for administrative assistance. B. M. P., S. A. J. and C. N. M. provided the idea for the analysis; S. W. N. conducted the analysis; S. W. N., S. A. J., C. N. M. and B. M. P wrote the paper. All authors were responsible for reviews and approval of the manuscript. None of the authors has any conflicts of interest.

\section{References}

1. NHS (2010) Health Survey for England - 2009 Trend Tables. London: NHSI Centre.

2. WHO (2000) Obesity: Preventing and Managing the Global Epidemic. Geneva: World Health Organization.

3. WHO/FAO (2003) Expert Consultation on Diet, Nutrition and the Prevention of Chronic Diseases Report of the Joint WHO/FAO Expert Consultation. Geneva: World Health Organization.

4. Kopelman P (2010) Symposium 1: overnutrition: consequences and solutions. Foresight Report: the obesity challenge ahead. Proc Nutr Soc 69, 80-85.

5. World Health Organization (2003) Diet, Nutrition, and the Prevention of Chronic Diseases. WHO Technical Report Series. Geneva: World Health Organization.

6. World Health Organization (2003) World Health Organization. Resolution WHA57.17. Global Strategy on Diet, Physical Activity and Health. Geneva: World Health Organization.

7. Mattes R (1996) Dietary compensation by humans for supplemental energy provided as ethanol or carbohydrate in fluids. Physiol Behav 59, 179-187.

8. DiMeglio DP \& Mattes RD (2000) Liquid versus solid carbohydrate: effects on food intake and body weight. Int $J$ Obes Relat Metab Disord 24, 794-800.

9. Mourao D, Bressan J \& Campbell W (2007) Effects of food form on appetite and energy intake in lean and obese young adults. Int J Obes (Lond) 31, 1688-1695.

10. Bray GA (2007) How bad is fructose? Am J Clin Nutr $\mathbf{8 6}$, 895-896.

11. Brown CM, Dulloo AG \& Yepuri G (2008) Fructose ingestion acutely elevates blood pressure in healthy young humans. Am J Physiol Regul Integr Comp Physiol 294, R730-R737.

12. Choi HK \& Curhan G (2008) Soft drinks, fructose consumption, and the risk of gout in men: prospective cohort study. BMJ 336, 309-312.

13. Stanhope KL \& Havel PJ (2008) Endocrine and metabolic effects of consuming beverages sweetened with fructose, glucose, sucrose, or high-fructose corn syrup. Am J Clin Nutr 88, 1733S-1737S

14. Stanhope KL, Schwarz JM \& Keim NL (2009) Consuming fructose-sweetened, not glucose-sweetened, beverages increases visceral adiposity and lipids and decreases insulin sensitivity in overweight/obese humans. J Clin Invest 119, $1322-1334$

15. Malik VS, Schulze MB \& Hu FB (2006) Intake of sugarsweetened beverages and weight gain: a systematic review. Am J Clin Nutr 84, 274-288.

16. Vartanian LR, Schwartz MB \& Brownell KD (2007) Effects of soft drink consumption on nutrition and health: a systematic review and meta-analysis. Am J Public Health 97, 667-675.
17. Johnson L, Mander AP \& Jones LR (2007) Is sugar-sweetened beverage consumption associated with increased fatness in children? Nutrition 23, 557-563.

18. Mueller NT, Odegaard A \& Anderson K (2010) Soft drink and juice consumption and risk of pancreatic cancer: The Singapore Chinese Health Study. Cancer Epidemiol Biomark Prev 19, $447-455$.

19. Sanigorski AM, Bell AC \& Swinburn BA (2007) Association of key foods and beverages with obesity in Australian schoolchildren. Public Health Nutr 10, 152-157.

20. Bazzano LA, Li TY \& Joshipura KJ (2008) Intake of fruit, vegetables, and fruit juices and risk of diabetes in women. Diabetes Care 31, 1311-1317.

21. Flood-Obbagy JE \& Rolls BJ (2009) The effect of fruit in different forms on energy intake and satiety at a meal. Appetite 52, 416-422.

22. Odegaard AO, Koh W-P \& Arakawa K (2010) Soft drink and juice consumption and risk of physician-diagnosed incident type 2 diabetes. Am J Epidemiol 171, 701-708.

23. Daniels MC \& Popkin BM (2010) Impact of water intake on energy intake and weight status: a systematic review. Nutr Rev 68, 505-521.

24. Popkin BM, D'Anci KE \& Rosenberg IH (2010) Water, hydration, and health. Nutr Rev 68, 439-458.

25. Popkin BM (2010) Patterns of beverage use across the lifecycle. Physiol Behav 100, 4-9.

26. Duffey KJ, Gordon-Larsen P, Steffen LM, et al. (2010) Drinking caloric beverages increases the risk of adverse cardiometabolic outcomes in the Coronary Artery Risk Development in Young Adults (CARDIA) study. Am J Clin Nutr 92, 954-959.

27. Barquera S, Campirano F \& Bonvecchio A (2010) Caloric beverage consumption patterns in Mexican children. Nutr J 9, 47.

28. Rivera JA, Muñoz-Hernández O \& Rosas-Peralta M (2008) Consumo de bebidas para una vida saludable: recomendaciones para la población (Beverage consumption for a healthy life: recommendations for the Mexican population). Salud Publica Mexico 50, 173-195.

29. Brownell KD, Farley T \& Willett WC (2009) The public health and economic benefits of taxing sugar-sweetened beverages. $N$ Engl J Med 361, 1599-1605.

30. Brownell KD \& Frieden TR (2009) Ounces of prevention the public policy case for taxes on sugared beverages. $N$ Engl J Med 360, 1805-1808.

31. Tiffin R \& Arnoult M (2011) The public health impacts of a fat tax. Eur J Clin Nutr 65, 427-433.

32. Mytton O, Gray A \& Rayner M (2007) Could targeted food taxes improve health? J Epidemiol Comm Health 61, 689-694.

33. Nnoaham KE, Sacks G \& Rayner M (2009) Modelling income group differences in the health and economic impacts of targeted food taxes and subsidies. Int I Epidemiol 38, $1324-1333$

34. Food Standards Agency \& Department of Health (2010) National Diet and Nutrition Survey: Headline Results from Year 1 of the Rolling Programme (2008/2009). London: Food Standards Agency and Department of Health.

35. Office of National Statistics Living Costs and Food Survey, http://www.statistics.gov.uk/ssd/surveys/expenditure_food_ survey.asp

36. Timmer CP, Falcon WP \& Pearson SR (1984) Food Policy Analysis. Baltimore, MD: The Johns Hopkins University Press for the World Bank

37. Haines PS, Guilkey DK \& Popkin BM (1988) Modeling food consumption decision as a two step process. Am J Agric Econ 70, 543-552. 
38. Stata Corporation (2009) Stata, Release 11. College Station, TX: Stata Corporation.

39. Duffey KJ, Huybrecht I, Mouratidou T, et al. (2011) Beverage consumption among European adolescents in the HELENA Study. Eur J Clin Nutr (Epublication ahead of print version 28 September 2011).

40. Barquera S, Hernández L \& Tolentino ML (2008) Energy from beverages is on the rise among Mexican adolescents and adults. J Nutr 138, 2454-2461.

41. UK Department of Health (2011) Statement of the Calorie Reduction Group. http://www.dh.gov.uk/en/Publications andstatistics/Publications/PublicationsPolicyAndGuidance/ DH_127553 (accessed September 2011).

42. Duffey KJ, Gordon-Larsen P \& Shikany JM (2010) Food price and diet and health outcomes: 20 years of the CARDIA Study. Arch Intern Med 170, 420-426.

43. Andreyeva T, Long MW \& Brownell KD (2009) The impact of food prices on consumption: a systematic review of research on the price elasticity of demand for food. Am J Public Health 100, 216-222.

44. Finkelstein EA, Zhen C \& Nonnemaker J (2010) Impact of targeted beverage taxes on higher- and lower-income households. Arch Intern Med 170, 2028-2034.

45. British Soft Drinks Association (2009) Trusted Innovation: The 2009 UK Soft Drinks Report. London: BSDA.

46. Gallet CA (2007) The demand for alcohol: a meta-analysis of elasticities. Aust J Agric Resour Econ 51, 121-135.

47. Gibney MJ, Marinos E, Ljunggvist O, et al. (2005) Clinical Nutrition (The Nutrition Society Textbook). London: WileyBlackwell.

48. Purshouse RC, Meier PS \& Brennan A (2010) Estimated effect of alcohol pricing policies on health and health economic outcomes in England: an epidemiological model. Lancet 375, 1355-1364.

49. Liang L, Chaloupka F \& Nichter M (2003) Prices, policies and youth smoking, May 2001. Addiction 98, 105-122.

50. Ranson MK, Jha P \& Chaloupka FJ (2002) Global and regional estimates of the effectiveness and cost-effectiveness of price increases and other tobacco control policies. Nicotine Tob Res 4, 311-319.

51. Warner KE (2005) Tobacco policy in the United States: lessons for the obesity epidemic. In Policy Challenges in Modern Health Care, pp. 99-114 [D Mechani, LB Rogut and DC Colby, et al., editors]. New Brunswick, NJ: Rutgers University Press.
52. Popkin BM (2011) Agricultural policies, food and public health. EMBO Rep 12, 11-18.

53. Muller M, Schoonover H \& Wallinga D (2007) Considering the Contribution of US Food and Agricultural Policy to the Obesity Epidemic: Overview and Opportunities. Minneapolis, MN: Institute for Agriculture and Trade Policy.

54. Herman DR, Harrison GG \& Afifi AA (2008) Effect of a targeted subsidy on intake of fruits and vegetables among low-income women in the special supplemental nutrition program for women, infants, and children. Am J Pub Health 98, 98-105.

55. Kamerow D (2010) The case of the sugar sweetened beverage tax. BMJ 341, c3719.

56. Heitmann BL, Lissner L \& Osler M (2000) Do we eat less fat, or just report so? Int J Obes Relat Metab Disord 24, 435-442.

57. Rennie KL, Coward A \& Jebb SA (2007) Estimating underreporting of energy intake in dietary surveys using an individualised method. Br J Nutr 97, 1169-1176.

58. Rennie KL, Jebb SA \& Wright A (2005) Secular trends in under-reporting in young people. Br J Nutr 93, 241-247.

59. Black AE, Goldberg GR \& Jebb SA (1991) Critical evaluation of energy intake data using fundamental principles of energy physiology: 2. Evaluating the results of published surveys. Eur J Clin Nutr 45, 583-599.

60. Erinosho TO, Thompson OM \& Moser RP (2011) Fruit and vegetable intake of US adults: comparing intake by mode of survey administration. J Am Diet Assoc 111, 408-413.

61. Wilks DC, Mander AP \& Jebb SA (2011) Dietary energy density and adiposity: employing bias adjustments in a metaanalysis of prospective studies. BMC Public Health 11, 48.

62. Lissner L, Heitmann BL \& Lindroos AK (1998) Measuring intake in free-living human subjects: a question of bias. Proc Nutr Soc 57, 333-339.

63. Einav L, Leibtag E \& Nevo A (2008) On the Accuracy of Nielsen Homescan Data. Washington, DC: USDA.

64. Einav L, Leibtag E \& Nevo A (2010) Recording discrepancies in Nielsen Homescan data: are they present and do they matter? Quant Market Econ 8, 207-239.

65. Zhen C, Taylor JL \& Muth MK (2009) Understanding differences in self-reported expenditures between household scanner data and diary survey data: a comparison of homescan and consumer expenditure survey. Rev Agric Econ 31, $470-492$. 
Appendix 1. Beverage group categories for the UK Data Archive National Food Survey - food expenditure data

\begin{tabular}{|c|c|c|}
\hline Name & Food description & Unit \\
\hline Water & Mineral water & $\mathrm{fl} \mathrm{oz}$ \\
\hline \multirow[t]{3}{*}{ Coffee (unsweetened or sweetened) } & Coffee, bean and grounded & $\mathrm{Oz}$ \\
\hline & Coffee, instant & $\mathrm{Oz}$ \\
\hline & Coffee, essences & $\mathrm{fl} \mathrm{oz}$ \\
\hline Tea (unsweetened or sweetened) & Tea* $^{*}$ & $\mathrm{oz}$ \\
\hline \multirow[t]{4}{*}{ Milk, low-fat and skimmed (low/reduced-fat) } & Skimmed milk & Im pt \\
\hline & Fully skimmed milk & \\
\hline & Semi- and others skimmed milk & \\
\hline & Other milk, including skimmed & \\
\hline \multirow[t]{11}{*}{ Milk, high-fat and infant (whole/high-fat) } & Milk, liquid & Im pt \\
\hline & 'UHT’ liquid milk & \\
\hline & Sterilised milk, full price & \\
\hline & Other liquid milk & \\
\hline & Milk, condensed & \\
\hline & Milk, dried, national & \\
\hline & Infant milks & \\
\hline & Milk, instant & \\
\hline & Other milk, not skimmed & \\
\hline & Other milks & \\
\hline & Cream & \\
\hline \multirow[t]{2}{*}{ Chocolate, Horlicks, Ovaltine (sweetened dairy) } & Cocoa, drinking chocolate and instant chocolate & $\mathrm{Oz}$ \\
\hline & Branded food drinks & $\mathrm{oz}$ \\
\hline \multirow[t]{3}{*}{ Low-nutritive/energy (diet sweetened) } & Soft drinks, low energy & $\mathrm{fl} \mathrm{oz}$ \\
\hline & Soft drinks, low energy, concentrated & \\
\hline & Soft drinks, low energy, unconcentrated & \\
\hline \multirow[t]{2}{*}{ Soda and fruit drinks with added sugar (sugar sweetened) } & Soft drinks, concentrated & $\mathrm{fl} \mathrm{oz}$ \\
\hline & Soft drinks, unconcentrated & \\
\hline Fruit juice & Fruit juices† & $\mathrm{fl} \mathrm{Oz}$ \\
\hline Vegetable juice & Vegetable juices & $\mathrm{fl} \mathrm{oz}$ \\
\hline \multirow{10}{*}{ Alcohol } & Low-alcohol beers, lagers and ciders & $\mathrm{cl}$ \\
\hline & Beers & $\mathrm{cl}$ \\
\hline & Lager and continental beers & $\mathrm{cl}$ \\
\hline & Ciders and perry & $\mathrm{cl}$ \\
\hline & Wine & $\mathrm{cl}$ \\
\hline & Wine (not full strength) spirits with additions & $\mathrm{cl}$ \\
\hline & Fortified wines & $\mathrm{cl}$ \\
\hline & Spirits & $\mathrm{cl}$ \\
\hline & Liqueurs & $\mathrm{cl}$ \\
\hline & Alco-Pops & $\mathrm{ml}$ \\
\hline
\end{tabular}

fl oz, Fluid ounce; Im pt, imperial pint; UHT, ultra-high temperature.

*The lone 'tea' code in the British National Food Survey (NFS) data did not include instant tea or herbal tea, which was part of a 'miscellaneous' code.

†The 'fruit juices' code in the NFS data did not include juice concentrate, which was part of the 'dried fruit' code. 
Appendix 2. Mean 'diluent:powder' ratios from the 2000 UK Data Archive Food Intake and Expenditure Data*

\begin{tabular}{|c|c|c|c|c|c|c|c|}
\hline \multirow{2}{*}{$\begin{array}{l}\text { NFS data } \\
\text { Powder/concentrate }\end{array}$} & \multirow[b]{2}{*}{ Diluent† } & \multicolumn{6}{|c|}{ Diluent:powder ratio } \\
\hline & & Powder/concentrate & Median & Mean & SD & Minimum & Maximum \\
\hline Instant coffeeł & $\begin{array}{l}\text { Water and/or } \\
\text { milk }\end{array}$ & $\begin{array}{l}\text { Instant coffee, Instant cappuccino, whitener, } \\
\text { no sugar Instant cappuccino, whitener, sugar, } \\
\text { Instant coffee, decaffeinated }\end{array}$ & 169 & 173 & 78 & 3 & 620 \\
\hline Tea§ & Water & $\begin{array}{l}\text { Instant tea, freeze-dried, lemon Instant tea, } \\
\text { milk powder added }\end{array}$ & 45 & 71 & 73 & 10 & 383 \\
\hline Diet soft drinks\| & Water & $\begin{array}{l}\text { Fruit drink, etc., containing blackcurrant, Barley } \\
\text { water, diet, no blackcurrant, High juice drink, low } \\
\text { sugar, Ribena light, low sugar, Ribena, no } \\
\text { added sugar } \\
\text { Fruit drink, etc., no blackcurrant } \\
\text { Barley water, diet, containing blackcurrant }\end{array}$ & 5 & 6 & 5 & 0.3 & 42 \\
\hline Regular soft drinks\| & Water & $\begin{array}{l}\text { Lime juice cordial, Fruit drink, squash, no blackcurrant } \\
\text { Super-concentrated crush } \\
\text { Ribena original, Cordial } \\
\text { High juice drink, no blackcurrant } \\
\text { High juice drink, containing blackcurrant, Fruit } \\
\quad \text { drink, squash, containing blackcurrant, Barley } \\
\quad \text { water } \\
\text { High juice, red. sugar, no blackcurrant, } \\
\text { Fruit drink, containing blackcurrant }\end{array}$ & 5 & 6 & 7 & 0.3 & 155 \\
\hline $\begin{array}{l}\text { Dairy and chocolate } \\
\text { drinks }\end{array}$ & $\begin{array}{l}\text { Water and/or } \\
\text { milk }\end{array}$ & $\begin{array}{l}\text { Cocoa powder, Milk shake powder, Drinking } \\
\text { chocolate, instant, Cadbury highlights, } \\
\text { chocolate instant, Instant malted drinks }\end{array}$ & 17 & 23 & 22 & 2 & 266 \\
\hline Branded drinks & $\begin{array}{l}\text { Water and/or } \\
\text { milk }\end{array}$ & $\begin{array}{l}\text { Horlicks malted food drink } \\
\text { Ovaltine not Ovaltine instant } \\
\text { Horlicks powder instant } \\
\text { Ovaltine instant low fat } \\
\text { Horlicks low fat instant, chocolate } \\
\text { Horlicks chocolate malted food } \\
\text { drink Bournvita not instant }\end{array}$ & 12 & 18 & 27 & 3 & 287 \\
\hline
\end{tabular}

red. sugar, Red-coloured sugar used in some beverages.

* This table shows basic descriptive statistics for diluent:powder ratios, which were calculated for various powders and concentrates using the 2000 UK Food Intake \& Expenditure data. The median ratio was used to reconstitute the corresponding powder or concentrate in the National Food Survey (NFS) and the Expenditure and Food Survey where the dry weight of the powder or concentrate was reported.

† Milk as a diluent codes include: $602,603,604,608,610,613,616,622,694,8543,8544,9132$.

$\ddagger$ The ratios for both coffee beans and coffee essences could not be calculated, since their weights were reported in reconstituted form in the Food \& Expenditure data. We used our own calculations: coffee beans $=42$ and coffee essences $=4$.

$\S$ The NFS code for tea only included tea bags. Since tea bags were reported in reconstituted form in the Food \& Expenditure data, we calculated the ratios for instant tea $=45$ and instant herbal tea $=16$. After consideration, we decided that the instant tea ratio was more comparable with tea bags.

$\|$ We changed the ratio for soft drinks from 4 to 5 to match the 2008 'Family Food' report, Table 1.1, footnote c.

Appendix 3. Descriptive statistics on beverage consumption in Britain 
Nesitish Journal of Nutrition

Table A1. Daily per capita and per consumer beverage consumption ( $\mathrm{kJ} / \mathrm{d}$ and $\mathrm{ml} / \mathrm{d})$ among children in Britain*

\begin{tabular}{|c|c|c|c|c|c|c|c|c|c|c|c|c|}
\hline & \multicolumn{6}{|c|}{ Ages $1.5-4.5$ years $\dagger$} & \multicolumn{6}{|c|}{ Ages $4-18$ years $\ddagger$} \\
\hline & \multicolumn{3}{|c|}{1992} & \multicolumn{3}{|c|}{$2008-9$} & \multicolumn{3}{|c|}{1997} & \multicolumn{3}{|c|}{$2008-9$} \\
\hline & $\begin{array}{c}\text { Per } \\
\text { capita }\end{array}$ & $\begin{array}{c}\text { Consumed } \\
(\%)\end{array}$ & $\begin{array}{c}\text { Per } \\
\text { consumer§ }\end{array}$ & $\begin{array}{c}\text { Per } \\
\text { capita }\end{array}$ & $\begin{array}{c}\text { Consumed } \\
(\%)\end{array}$ & $\begin{array}{c}\text { Per } \\
\text { consumer§ }\end{array}$ & $\begin{array}{c}\text { Per } \\
\text { capita }\end{array}$ & $\begin{array}{c}\text { Consumed } \\
(\%)\end{array}$ & $\begin{array}{c}\text { Per } \\
\text { consumer§ }\end{array}$ & $\begin{array}{c}\text { Per } \\
\text { capita }\end{array}$ & $\begin{array}{c}\text { Consumed } \\
(\%)\end{array}$ & $\begin{array}{c}\text { Per } \\
\text { consumer§}\end{array}$ \\
\hline \multicolumn{13}{|l|}{ Energy contribution $(\mathrm{kJ} / \mathrm{d})$} \\
\hline High-fat milk & 510 & 82 & 623 & 565 & $69+$ & 828 & 192 & 44 & 439 & $138 \ddagger$ & $30 \ddagger$ & 464 \\
\hline Reduced-fat milk & 100 & 33 & 301 & 138 & 42 & 331 & 155 & 52 & 301 & 159 & 58 & 276 \\
\hline Sweetened dairy & 130 & 90 & 146 & 88 & $21 \dagger$ & 406 & 63 & 21 & 297 & $105 \ddagger$ & $30 \ddagger$ & 356 \\
\hline Alcohol & 0 & 1 & 21 & 0 & 0 & 0 & 42 & 8 & 544 & 92 & 8 & 1100 \\
\hline Spirits/liqueurs & 0 & 0 & 0 & 0 & 0 & 0 & 4 & 2 & 247 & 25 & 3 & 808 \\
\hline Wine & 0 & 1 & 21 & 0 & 0 & 0 & 4 & 2 & 192 & 4 & 3 & 163 \\
\hline Beer/cider/alcopops & 0 & 0 & 21 & 0 & 0 & 0 & 33 & 6 & 611 & 63 & 6 & 1038 \\
\hline Sodas/fruit drinks & 280 & 86 & 326 & $88 \dagger$ & $52 \dagger$ & 172 & 285 & 81 & 351 & 318 & 79 & 402 \\
\hline Low-nutritive 'diet'-sweetened drinks & 13 & 49 & 25 & 13 & 61 & 17 & 21 & 72 & 33 & $13 \ddagger$ & $59 \ddagger$ & 21 \\
\hline Juices & 67 & 39 & 176 & 109 & $58 \dagger$ & 188 & 92 & 44 & 213 & $130 \ddagger$ & 53 & 247 \\
\hline Unsweetened coffee/tea & 4 & 18 & 29 & 4 & 17 & 21 & 8 & 17 & 54 & 4 & $15 \ddagger$ & 38 \\
\hline Sweetened coffee & 8 & 6 & 163 & 0 & 0 & 172 & 25 & 11 & 218 & 13 & 7 & 172 \\
\hline Sweetened tea & 79 & 30 & 264 & $21 \dagger$ & $16 \dagger$ & 121 & 67 & 31 & 218 & 38 & 24 & 159 \\
\hline Other energy & 88 & 33 & 268 & $38 \dagger$ & 21 & 172 & 92 & 38 & 247 & 79 & 39 & 209 \\
\hline Total energy from beverages & & 285 & & & 249 & & & 228 & & & 250 & \\
\hline Total energy from all sources & & 1137 & & & 1173 & & & 1725 & & & 1759 & \\
\hline Total energy from beverages (\%) & & 25 & & & $21 \dagger$ & & & 13 & & & 14 & \\
\hline \multirow{2}{*}{\multicolumn{13}{|c|}{$\begin{array}{l}\text { Volume consumed }(\mathrm{ml} / \mathrm{d}) \\
\text { Water intake }\end{array}$}} \\
\hline \multicolumn{9}{|l|}{ Water intake } & & & & \\
\hline Water in food & & 235 & & & $357 \dagger$ & & & 400 & & & 457 & \\
\hline Water in beverages & & 771 & & & $804 \dagger$ & & & 854 & & & 1037 & \\
\hline Water total from all sources & & 1007 & & & 1161 & & & 1254 & & & 1494 & \\
\hline \multicolumn{13}{|l|}{ Beverage pattern } \\
\hline \multicolumn{13}{|l|}{ No energy } \\
\hline Water as a beverage & 180 & 77 & 235 & 173 & 74 & 234 & 97 & 51 & 189 & $307 \ddagger$ & $80 \ddagger$ & 383 \\
\hline Unsweetened coffee and tea & 9 & 18 & 51 & 12 & 17 & 71 & 33 & 17 & 198 & 26 & 15 & 169 \\
\hline \multicolumn{13}{|l|}{ High energy } \\
\hline High-fat milk & 180 & 82 & 220 & 208 & 69 & 303 & 69 & 44 & 158 & 51 & $30 \ddagger$ & 171 \\
\hline Reduced-fat milk & 52 & 33 & 157 & 79 & 42 & 186 & 81 & 52 & 158 & 87 & 58 & 149 \\
\hline Sweetened dairy & 42 & 90 & 47 & $30 \dagger$ & $21 \dagger$ & 140 & 20 & 21 & 92 & 31 & $30 \ddagger$ & 104 \\
\hline Alcohol & 0 & 1 & 8 & 0 & 0 & 0 & 28 & 8 & 358 & 44 & 8 & 522 \\
\hline Soda/fruit drinks & 181 & 86 & 211 & 79 & $52 \dagger$ & 153 & 212 & 81 & 264 & 230 & 79 & 290 \\
\hline \multicolumn{13}{|l|}{ Low energy } \\
\hline Low-nutritive 'diet'-sweetened drinks & 81 & 49 & 165 & $185 \dagger$ & 61 & 304 & 220 & 72 & 307 & $170 \ddagger$ & $59 \ddagger$ & 289 \\
\hline Juices & 48 & 39 & 122 & 69 & $58 \dagger$ & 118 & 63 & 44 & 145 & 81 & $53 \ddagger$ & 154 \\
\hline Other energy & 62 & 33 & 186 & 26 & 21 & 124 & 86 & 38 & 227 & 73 & 39 & 187 \\
\hline Total $\mathrm{ml}$ of beverages & \multirow{2}{*}{\multicolumn{3}{|c|}{$1689^{835}$}} & \multirow{2}{*}{\multicolumn{3}{|c|}{$141^{860 \dagger}$}} & \multicolumn{3}{|c|}{909} & 100 & & \\
\hline Number of observations & & & & & 141 & & & 1798 & & \multicolumn{3}{|c|}{462} \\
\hline Days of intake\| & & 7 adjusted & & & 4 & & & 7 adjusted tc & & & 4 & \\
\hline
\end{tabular}

* Results are weighted to be nationally representative where weights were available (weights applied to 1997 and 2008-9 data).

$\dagger 2008-9$ is statistically different $(P<0.01)$ from 1992.

§Unable to determine statistical difference between years for per consumer consumption since the sample population that consumes the beverage varies from beverage to beverage.

|| The 1992 and 1997 surveys have $7 \mathrm{~d}$ recalls, but adjusted by bootstrap sampling to allow comparisons with 2008-9 on a $4 \mathrm{~d}$ basis. 
Table A2. Daily per capita and per consumer beverage consumption ( $\mathrm{kJ} / \mathrm{d}$ and $\mathrm{ml} / \mathrm{d})$ among adults (19-64 years) in Britain*

\begin{tabular}{|c|c|c|c|c|c|c|c|c|c|}
\hline & \multicolumn{3}{|c|}{$1986-7$} & \multicolumn{3}{|c|}{$2000-1 \dagger$} & \multicolumn{3}{|c|}{$2008-9 \neq \S$} \\
\hline & $\begin{array}{c}\text { Per } \\
\text { capita }\end{array}$ & $\begin{array}{c}\text { Consumed } \\
(\%)\end{array}$ & $\begin{array}{c}\text { Per } \\
\text { consumer\| }\end{array}$ & $\begin{array}{c}\text { Per } \\
\text { capita }\end{array}$ & $\begin{array}{c}\text { Consumed } \\
(\%)\end{array}$ & $\begin{array}{c}\text { Per } \\
\text { consumer\| }\end{array}$ & $\begin{array}{c}\text { Per } \\
\text { capita }\end{array}$ & $\begin{array}{c}\text { Consumed } \\
(\%)\end{array}$ & $\begin{array}{c}\text { Per } \\
\text { consumer\|l}\end{array}$ \\
\hline \multicolumn{10}{|l|}{ Energy contribution (kJ/d) } \\
\hline High-fat milk & 155 & 49 & 314 & $54 \dagger$ & $15 \dagger$ & 351 & $42 \ddagger$ & $13 \ddagger$ & 331 \\
\hline Reduced-fat milk & 42 & 24 & 172 & $117 \dagger$ & $50 \dagger$ & 234 & $100 \ddagger$ & $54 \ddagger$ & 184 \\
\hline Sweetened dairy & 63 & 16 & 368 & $29 \dagger$ & 12 & 255 & 38 & 12 & 310 \\
\hline Alcohol & 565 & 62 & 916 & 619 & 65 & 925 & $770 \ddagger$ & 64 & 1205 \\
\hline Spirits/liqueur & 54 & 19 & 272 & 59 & 17 & 314 & 100 & 17 & 573 \\
\hline Wine & 121 & 32 & 385 & 163 & 35 & 456 & 205 & 36 & 565 \\
\hline Beer/cider/alcopops & 389 & 40 & 975 & 397 & 42 & 916 & 469 & 40 & 1159 \\
\hline Sodas/fruit drinks & 113 & 49 & 226 & $155 \dagger$ & 46 & 335 & $209 \ddagger$ & $54 \S$ & 381 \\
\hline Low-nutritive 'diet'-sweetened drinks & 0 & 12 & 8 & 8 & $36 \dagger$ & 25 & 8 & $35 \ddagger$ & 17 \\
\hline Juices & 54 & 34 & 163 & 79 & 40 & 192 & $84 \ddagger$ & 41 & 205 \\
\hline Unsweetened coffee/tea & 109 & 69 & 159 & $71 \dagger$ & $59+$ & 121 & $75 \ddagger$ & $68 \S$ & 109 \\
\hline Sweetened coffee & 276 & 63 & 435 & $209 \dagger$ & 64 & 326 & $105 \ddagger \S$ & $37 \ddagger \S$ & 289 \\
\hline Sweetened tea & 339 & 60 & 569 & $163 \dagger$ & $39+$ & 414 & $117 \ddagger$ & $40 \ddagger$ & 293 \\
\hline Other energy & 619 & 84 & 741 & $372 \dagger$ & 81 & 464 & $251 \ddagger \S$ & $65 \ddagger \S$ & 385 \\
\hline Total energy from beverages & & 411 & & & 359 & & & 376 & \\
\hline Total energy from all sources & & 2064 & & & 1978 & & & 1950 & \\
\hline Total energy from beverages (\%) & & 19 & & & 18 & & & 18 & \\
\hline \multicolumn{10}{|l|}{ Volume consumed $(\mathrm{ml} / \mathrm{d})$} \\
\hline \multicolumn{10}{|l|}{ Water intake } \\
\hline Water in food & & 544 & & & 571 & & & $610 \ddagger$ & \\
\hline Water in beverages & & 1555 & & & $1715 \dagger$ & & & $1884 \ddagger$ & \\
\hline Water total from all sources & & 2099 & & & $2286 \dagger$ & & & $2494 \ddagger$ & \\
\hline \multicolumn{10}{|l|}{ Beverage pattern } \\
\hline \multicolumn{10}{|l|}{ No energy } \\
\hline Water as a beverage & 75 & 44 & 169 & $268 \dagger$ & $66+$ & 408 & $432 \ddagger \S$ & $78 \mp \S$ & 556 \\
\hline Unsweetened coffee and tea & 440 & 69 & 635 & $326 \dagger$ & 59 & 555 & $451 \S$ & 68 & 664 \\
\hline \multicolumn{10}{|l|}{ High energy } \\
\hline High-fat milk & 56 & 49 & 116 & $20 \dagger$ & $15 \dagger$ & 131 & $16 \ddagger$ & $13 \ddagger$ & 124 \\
\hline Reduced-fat milk & 23 & 24 & 98 & $65 \dagger$ & $50 \dagger$ & 131 & $55 \ddagger$ & $54 \ddagger$ & 103 \\
\hline Sweetened dairy & 24 & 16 & 145 & $11 \dagger$ & 12 & 93 & $13 \ddagger$ & 12 & 102 \\
\hline Alcohol & 316 & 62 & 511 & 336 & 66 & 511 & 405 & 64 & 635 \\
\hline Soda/fruit drinks & 76 & 49 & 154 & $108 \dagger$ & 46 & 236 & $139 \ddagger$ & 54 & 256 \\
\hline \multicolumn{10}{|l|}{ Low energy } \\
\hline Low-nutritive 'diet'-sweetened drinks & 17 & 12 & 144 & $99 \dagger$ & $36 \dagger$ & 272 & $102 \ddagger$ & $35 \ddagger$ & 290 \\
\hline Juices & 37 & 34 & 108 & $59+$ & 40 & 147 & 55 & 41 & 133 \\
\hline Other energy & 572 & 84 & 683 & 509 & 80 & 633 & $301 \ddagger \S$ & $65 \ddagger \S$ & 460 \\
\hline Total $\mathrm{ml}$ of beverages & 1637 & 100 & 1637 & $1801 \dagger$ & 100 & 1801 & $1970 \ddagger$ & 100 & 1970 \\
\hline Number of observations & & 2030 & & & 1724 & & & 434 & \\
\hline Days of intakeq & & 7 adjusted to 4 & & & 7 adjusted to 4 & & & 4 & \\
\hline
\end{tabular}

${ }^{*}$ Results are weighted to be nationally representative where weights were available (weights applied to adults 2000-1 and 2008-9).

†2000-1 is statistically different $(P<0.01)$ from $1986-7$.

$\ddagger 2008-9$ is statistically different $(P<0.01)$ from $1986-7$.

$\S 2008-9$ is statistically different $(P<0.01)$ from 2000-1.

\|Unable to determine statistical difference between years for per consumer consumption since the sample population that consumes the beverage varies from beverage to beverage.

I The 1986-7 and 2000-1 surveys have $7 \mathrm{~d}$ recalls, but adjusted by bootstrap sampling to allow comparisons with $2008-9$ on a $4 \mathrm{~d}$ basis. 
Table A3. Great Britain beverage group trends: volume purchased per household per week $(\mathrm{ml})^{*}$

\begin{tabular}{|c|c|c|c|c|c|c|c|c|}
\hline \multirow[b]{2}{*}{ Beverage category } & \multicolumn{8}{|c|}{ Beverage purchases by British households per week (ml) } \\
\hline & 1975 & 1980 & 1985 & 1990 & 1995 & 2000 & 2001 & 2007 \\
\hline High-fat milk & 3056 & 2711 & 2190 & 1469 & 982 & 847† & 764 & $579 \S \| \uparrow$ \\
\hline Reduced-fat milk & 8 & 23 & 258 & 763 & 1207 & $1278 \dagger \ddagger$ & 1191 & $1301 \S \| \rrbracket$ \\
\hline Sweetened dairy & 294 & 279 & 271 & 316 & 246 & 275 & 149 & $134 \| 9$ \\
\hline Alcohol & NA & NA & NA & NA & 700 & 817 & 770 & 833 \\
\hline Sugar sweetened (soda/fruit drinks) & 512 & 607 & 771 & 940 & 1082 & $1189 \dagger$ & 1195 & $1142 \|$ \\
\hline Low-nutritive 'diet'-sweetened drinks & 5 & 12 & 40 & 134 & 468 & $483 † \ddagger$ & 464 & 472\|\| \\
\hline Juices & 47 & 105 & 177 & 231 & 284 & $342 \dagger \ddagger$ & 342 & $347 \| \pi$ \\
\hline $100 \%$ fruit juice & 46 & 104 & 175 & 229 & 282 & $340 t$ & 337 & 340\|\| \\
\hline Vegetable juice & 1 & 1 & 2 & 2 & 2 & 2 & 5 & 7\|\| \\
\hline Coffee & 3029 & 3260 & 3247 & 3003 & 2669 & 2522 & 2758 & 2920 \\
\hline Tea & 3417 & 3302 & 2782 & 2415 & 2253 & 1993†‡ & 1811 & $1644 \| \uparrow$ \\
\hline Water, bottled & NA & NA & 21 & 93 & 174 & $246 \ddagger$ & 215 & 2679 \\
\hline Sample size (no. of households) & 7405 & 7914 & 7102 & 7174 & 8011 & 6590 & 7450 & 6102 \\
\hline
\end{tabular}

NA, not available.

Source: British household expenditures and consumption from the 1975-2000 Family Expenditure Survey and the 2001-7 Expenditure and Food Survey.

* All results are weighted to be nationally representative.

†2000 is statistically different $(P<0.01)$ from 1975 .

$\ddagger 2000$ is statistically different $(P<0.01)$ from 1990 .

$\S 2007$ is statistically different $(P<0.01)$ from 2001 .

|| 2007 is statistically different $(P<0.01)$ from 1975 .

ๆ 2007 is statistically different $(P<0.01)$ from 1990 . 